\title{
Does paying service providers by results improve recovery outcomes for drug misusers in treatment in England?
}

Andrew Jones ${ }^{1}$, Matthias Pierce ${ }^{2}$, Matt Sutton ${ }^{3}$, Thomas Mason ${ }^{3}$, Tim Millar $^{4}$

${ }^{1}$ Centre for Epidemiology, University of Manchester, Manchester M13 9PL; ${ }^{2}$ Centre for Biostatistics, University of Manchester, Manchester M13 9PL; ${ }^{3}$ Manchester Centre for Health Economics, University of Manchester, Manchester M13 9PL; ${ }^{4}$ Centre for Mental Health \& Safety, University of Manchester, Manchester M13 9PL

Correspondence to andrew.jones@manchester.ac.uk

Word count: 3484

Competing Interests: Millar and Jones have received research funding from a UK treatment provider. Millar is an unpaid government advisor on drug misuse.

Contributors: TMi designed the study, with assistance from AJ and MP. AJ, TMi and MP agreed the analysis plans. AJ and MP performed the analysis. AJ drafted the manuscript with assistance from TMi, MP, MS and TMa.

Transparency declaration: The lead author affirms that this manuscript is an honest, accurate, and transparent account of the study being reported; that no important aspects of the study have been omitted; and that any discrepancies from the study as planned (and, if relevant, registered) have been explained.

Funding: This study was funded by the Department of Health. The views expressed in the publication are those of the authors and not necessarily those of the Department of Health.

Data Sharing: no additional data available.

Disclaimer: This report is independent research commissioned and funded by the Department of Health Policy Research Programme (Evaluation of the Drugs Recovery Payment by Results

This is the author manuscript accepted for publication and has undergone full peer review but has not been through the copyediting, typesetting, pagination and proofreading process, which may lead to differences between this version and the Version of Record. Please cite this article as doi: $10.1111 /$ add.13960

This article is protected by copyright. All rights reserved. 
Programme of Piloting).The views expressed in this publication are those of the author(s) and not necessarily those of the Department of Health, 'arms' length bodies and other government departments'.

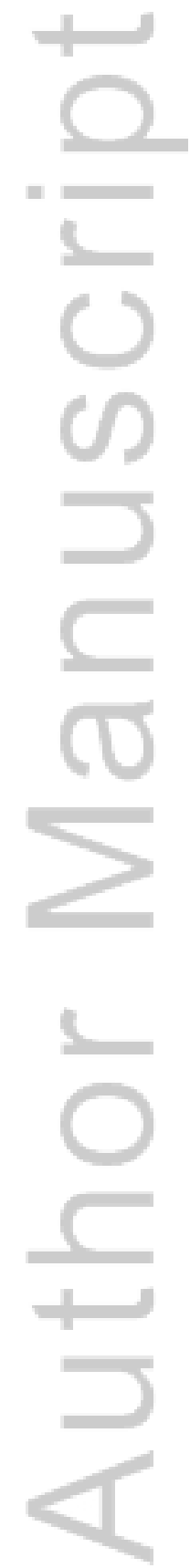

This article is protected by copyright. All rights reserved. 
Abstract

Aim: To compare drug recovery outcomes in commissioning areas included in a 'payment by results' scheme with all other areas.

Design: Observational and data linkage study of the National Drug Treatment Monitoring System, Office for National Statistics mortality database, and Police National Computer criminal records, for two years before and after introduction of the scheme. Pre-post controlled comparison compared outcomes in participating versus non-participating areas following adjustment for drug use, functioning and drug treatment status.

Setting: Drug services in England providing publicly-funded, structured treatment.

Participants: Adults in treatment (between 2010 and 2014): 154,175 (10,716 in participating areas, 143,459 non-participating) treatment journeys in the two years before, and 148,941 (10,012 participating, 138,929 non-participating) after the introduction of the scheme.

Intervention: Scheme participation, with payment to treatment providers based on patient outcomes versus all other areas.

Measurements: Rate of treatment initiation; waiting time (> or <= 3 weeks); treatment completion; and re-presentation; substance use; injecting; housing status; fatal overdose; acquisitive crime.

Findings: In participating areas, there were relative decreases in rates of: treatment initiation (Difference in Differences Odds Ratio (DID OR) $0.17,95 \% \mathrm{Cl} 0.14,0.21$ ); treatment completion (DID OR $0.60,95 \% \mathrm{Cl} 0.53,0.67$ ); and treatment completion without re-presentation (DID OR $0.63,95 \% \mathrm{Cl}$ $0.52,0.77)$ compared with non-participating areas. Within treatment, relative abstinence (DID OR $1.50,95 \% \mathrm{Cl} 1.30,1.72$ ) and non-injecting (DID OR 1.32, 95\% $\mathrm{Cl} 1.10,1.59$ ) rates were improved in participating areas. No significant changes in mortality, recorded crime, or housing status were associated with the scheme.

Conclusion: Drug addiction recovery services in England that are commissioned on a payment-byresults basis tend to have lower rates of treatment initiation and completion but higher rates of abstinence and non-injecting than other services.

This article is protected by copyright. All rights reserved. 
Introduction

Payment for performance (P4P) schemes have been applied in multiple settings across the health sector internationally [1], with the aim of improving services. There have been limited previous attempts to introduce payment incentives for addiction treatment service providers, and the evidence of its effects is equivocal $[2,3,4]$.

Payment-for-performance schemes typically base a proportion of payment to service providers on achievement of particular process indicators. Although improvement in patient outcomes is the ultimate mark of associated success, such evidence has been lacking [5]. However, interest in such schemes continues to develop and results of evaluations are starting to emerge [6]. A number of studies have identified positive effects of P4P schemes on quality of service delivery $[7,8,9,10]$ but "hardly any information is available about the effects of such schemes on healthcare quality and costs" [11]. Where a reduction in costs has been achieved "without detrimental effect on the quality of care" [12], improvements in patient outcome have not been identified.

In the UK, focus has been placed on the potential role of P4P in public service reform. The Audit Commission report on P4P for local services [13] describes a "potentially useful" approach, given: clearly defined service users and outcomes, measured baseline performance and reliable means of attributing changes to provider actions. The notion of paying for patient outcomes, as opposed to quantity of throughput, may seem laudable, but concern has been raised over the lack of evidence on improvement in health care to support its implementation [14]. In the absence of a conclusive evidence base, it is important to understand the impact of P4P. A field in which P4P schemes are being adopted is substance misuse treatment [15].

In April 2011 the Department of Health selected eight areas to participate in 'payment by results drug and alcohol recovery pilots'. Payments to providers were linked to client outcomes, representing recovery from substance misuse problems and reflecting national policy emphasis [16]. Concerns were raised about the use of this commissioning model $[15,17]$, based on practical aspects such as the breadth of payment outputs and the speed of introduction. Our evaluation of this programme provided an opportunity to measure the direct impact on client outcomes.

This article is protected by copyright. All rights reserved. 
Early findings from this evaluation [18] suggested poorer performance on a limited set of outcome measures. However, this related to the early phase (first nine months) of the programme, potentially reflecting a period of organisational flux rather than longer-term performance. In this paper, we extend the preliminary analysis in two ways: 1) inclusion of longer-term effects, measured over two years; and 2) consideration of a wider range of outcomes. The latter extends the indicator of treatment completion to consider changes in the rate of subsequent re-presentation for treatment, which is indicative of relapse. In addition, we consider rates of mortality, recorded offending and behavioural change during treatment. This provides a more complete account of the impact of the payment-for-performance programme.

The aim was to estimate the impact of the programme, by comparing changes in outcomes between the two years before and after the introduction of the scheme in participating areas, to the equivalent changes in the non-participating areas.

Methods

The Payment-for-Performance Programme

Eight commissioning areas (upper tier local authorities) within England participated, from April 2012 to March 2014. These were selected from 29 quality assessed volunteer applications. Five sites recommissioned services prior to the programme. Non-participating areas were free to operate their own commissioning models. These have traditionally been based on block grants, although, some elements of P4P may have been adopted. The payment models applied to all services within participating areas. All new adult service users were subject to payment tariffs. Existing service users were moved to P4P regimes during the study period.

Whilst participating areas were allowed some flexibility in the design of the P4P scheme, including variation in the proportion of payment attached to outcomes and freedom to include locally designed payment metrics, their schemes were required to adhere to a 'national outcomes framework'. Payments were aligned with three nationally-specified domains: (i) progression towards 
abstinence from presenting drug(s) of dependence; (ii) reduction in offending; and (iii) improved health and wellbeing. Three of the eight sites operated a 100\% P4P model, four operated at $20 \%$ to $30 \%$ and one at $10 \%$. Limited flexibility was permitted over the payment weights associated with the indicators, although measures such as successful completion of, and non-re-presentation to, treatment typically represented the highest share of P4P income [15].

Initial client assessments and care plans were conducted by Local Area Single Assessment \& Referral System (LASARS). LASARS collected information on client complexity, on the basis of which payment tariffs were set. The LASARS could be established independently of treatment services (as in five sites), though were often based in the same location

DesignTo test the effect of participation in this P4P programme we adopted a 'difference in differences' approach, designed to compare changes recorded in participating areas to those recorded in non-participating areas. Outcomes in the eight participating areas were aggregated within a single group, as were those from the 143 non-participating areas.

\section{Participants}

Study participants were drug misusers, aged $18+$, who attended structured treatment services in England during the two years before and after the introduction of P4P. Original power calculations, accounting for intra-cluster correlation and resulting design effects suggested the need for between 1,000 and 5,000 clients in participating areas (to detect a $5 \%$ change in completions or representations or a $0.4 \%$ change in mortality respectively).

Data

The National Drug Treatment Monitoring System (NDTMS) provided information about study participants. The analysis reported here is restricted to drug misusing service users, given differences in treatment and outcomes with primary alcohol misuse clients. NDTMS records information about: service users' characteristics and pre-treatment drug use; interventions received; and ongoing assessment of their drug use and health within treatment.

This article is protected by copyright. All rights reserved. 
Service users may have contact with multiple services over time. For the analysis, these episodes were considered part of the same sequence of treatment (hereafter: 'treatment journey') if no more than 21 days passed between interventions. Users may have more than one treatment journey within the analysis timeframes. We used the treatment journey as the unit of analysis.

The following outcomes, mapping to a core set of payment tariffs adopted in participating areas, were included: (a) whether a treatment intervention was initiated; (b) the waiting time to first intervention (< or >= 3 weeks); (c) status at treatment discharge (planned/unplanned, whether drug/dependence free); (d) re-presentation to treatment within 12 months of discharge; (e) abstinence from illicit substances and alcohol; ( $f$ ) injecting; and (g) acute housing problems or risk of eviction. The latter three items were based on the service user's self-reported situation at their latest assessment conducted within treatment, using the Treatment Outcomes Profile, a validated instrument which provides records changes in behaviour between treatment start and periodic, within-treatment reviews [19]. Non-representation to treatment is not necessarily a positive outcome as it may represent resistance to treatment rather than lack of treatment need. Nonetheless, it was considered to be positive by policymakers, who rewarded providers for achieving this outcome.

In addition, NDTMS data were linked to records from the Police National Computer and to mortality records from the Office of National Statistics (ONS), to measure recorded offending and deaths within the year of each treatment journey start. Linkage used the protocol described in similar work $[20,21]$ - a minimal identifier (initials, date of birth, gender and region of residence) was used to identify probabilistic matches between datasets. Suitable permissions and data extracts were obtained from the Ministry of Justice and ONS and identifiers were irreversibly encrypted. For outcomes requiring 12 month follow-up (deaths, convictions, re-presentations), data were truncated to 31st March 2013 to enable analysis within the study timeframe.

Power calculations showed sufficient power to measure differences in all outcomes between participating and non-participating areas but not between individual participating areas.

\section{Estimation}

This article is protected by copyright. All rights reserved. 
Each model estimated the change in a parameter comparing the pre-study period to the study period, for both participating and non-participating areas. For binary outcomes, logistic regression models were fitted with results reported as odds-ratios. The count outcome (acquisitive offences over one year) was modelled using a negative binomial model with results reported as rate ratios. The time-to-event outcome (drug-related death) was modelled using a Cox proportional hazard model with results reported as a Hazard Ratio. From each model, the difference in differences (DID) odds ratio/rate ratio/hazard ratio was calculated, defined as the change (from pre to post) in the P4P participating areas in relation to the change in the non-participating areas.

The models were adjusted for client complexity using thirteen covariates collected the client's initial assessment. These were: age; opioid/crack/benzodiazepine/cocaine/amphetamine/cannabis use; whether previously treated; coreceipt of mental health services; whether pregnant; employment status; injecting status; treatment referral type; years since first use of primary problem drug; parenting status; and housing status. To account for clustering at area and person levels, random intercepts were included for both levels. To account for clustering in the time-to-event models, a stratified Cox model was fitted with area as the stratification variable.

\section{Sensitivity analyses}

Not all service users in participating areas were included within the P4P payments framework from the outset of the scheme. We conducted sensitivity analyses excluding service users in participating areas who were not recorded in NDTMS as a P4P client. We also repeated the analysis using data from the second year (2013/14) only, since re-organisation within the first year may have moderated any effects. Finally, to account for potential selection bias among volunteer sites, we compared participating areas to non-participating areas that initially volunteered for the scheme.

\section{Results}


Cohort

A total of 303,116 new treatment journeys were available for analysis (Table 1). A total of 154,175 $(10,716$ participating, 143,459 non-participating) of these journeys occurred in the two years prior to, and 148,941 (10,012 participating, 138,929 non-participating) occurred after, the introduction of the scheme.

The proportion of service users who used opiates increased over time in participating areas compared to non-participating areas (Odds-Ratio 1.30, 95\% $\mathrm{Cl} 1.22,1.38$ ). Similar relative increases were identified for use of crack cocaine (OR 1.16, 95\% Cl 1.09,1.25), injecting (OR 1.10, 95\% CI 1.02,1.19) and co-receipt of mental health services (OR 1.17, 95\% $\mathrm{Cl} 1.09,1.27)$. There was also a relative reduction in cannabis use (OR $0.72,95 \% \mathrm{Cl} 0.68,0.77$ ).

\section{Table 1 here}

Table 2 shows outcomes for clients in participating and non-participating areas. The proportion of clients who started a treatment intervention following their initial presentation decreased substantially in participating areas but increased in non-participating areas (DID OR $0.17,95 \% \mathrm{CI}$ $0.14,0.21)$. Among those who started a treatment intervention, the proportion who waited less than three weeks before its commencement decreased in participating areas but increased in nonparticipating areas (DID OR $0.36,95 \% \mathrm{Cl} 0.31,0.42$ ). Unplanned discharges increased in participating areas and decreased in non-participating areas (DID OR 1.25, 95\% Cl 1.14,1.38).

The proportion of clients who successfully completed treatment within twelve months decreased (34\% to $24 \%$ ) in participating areas but increased ( $27 \%$ to $29 \%$ ) in non-participating areas (DID OR $0.60,95 \% \mathrm{Cl} 0.53,0.67)$. Correspondingly, the proportion of clients who both successfully completed treatment within six months and did not subsequently re-present to treatment within twelve months decreased ( $20 \%$ to $14 \%)$ in participating areas and increased (16\% to $17 \%)$ in nonparticipating areas (DID OR $0.63,95 \% \mathrm{Cl} 0.52,0.77$ ).

Among those clients who successfully completed treatment within six months, the proportion who did not then re-present within twelve months increased (82\% to $90 \%)$ in participating areas,

This article is protected by copyright. All rights reserved. 
compared to a more modest increase ( $85 \%$ to $86 \%$ ) in non-participating areas (DID OR $2.30,95 \% \mathrm{CI}$ $1.33,4.08)$.

At the latest within-treatment assessment, the proportion who reported no use of illicit substances or alcohol increased in participating areas ( $22 \%$ to $27 \%$ ) and decreased ( $23 \%$ to $22 \%$ ) in nonparticipating areas (DID OR 1.50, 95\% $\mathrm{Cl} 1.30,1.72$ ). The proportion who did not inject four weeks prior to follow-up (controlling for injecting at initial assessment) did not change substantively in participating or non-participating areas. The adjusted analysis indicated better injecting outcomes within participating versus non-participating areas (DID OR 1.321, 95\% Cl 1.10,1.59).

There was no statistically significant difference between participating and non-participating areas with respect to: the resolution of housing problems (DID OR 1.30, 95\% $\mathrm{Cl} 0.93,1.79$ ); acquisitive crime rate (DID Rate Ratio 0.93 per person, $95 \% \mathrm{Cl}$ 0.84,1.03); or mortality (DID Hazard Ratio 0.62 per 1,000 person years, $95 \% \mathrm{Cl} 0.28,1.36)$.

Table 2 here

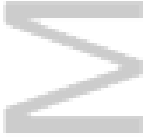

The sensitivity analyses (Table 3) had no substantial effect on inferences, with one exception. When analysis of injecting was restricted to $2013 / 14$, the difference-in -differences between participating and non-participating sites was no longer statistically significant at $p<0.05$ (DID OR $0.83,95 \% \mathrm{CI}$ $0.68,1.01)$.

Table 3 here

\section{Discussion}

Summary of results

This article is protected by copyright. All rights reserved. 
After P4P was introduced, clients in participating areas, waited longer to access treatment, were more likely to experience an unplanned discharge from treatment and were less likely to successfully complete their treatment, or complete without re-presentation for further treatment. However, the scheme was associated with service users reporting abstinence from illicit substances and alcohol and with a lower rate of injecting whilst in treatment. Further, among the subset of clients who did successfully complete treatment, those in participating areas were less likely than those in nonparticipating areas to return to treatment within one year.

\section{Limitations:}

Participation in the P4P scheme was voluntary. This non-random selection of participating areas places limits on the causal inference that can be drawn. Nonetheless, sensitivity analysis, comparing participating areas with volunteer areas not selected for the scheme, found comparable results.

There was considerable variation in the design of schemes within the eight participating areas, a feature that was beyond the control of the current study. Initial calculations indicated the need to combine data for these areas in order to achieve sufficient power. Differences in outcomes by scheme design could not be considered as this would require larger cohorts than were available for analysis. In the current analysis, large effects in particular sites may have affected the overall results.

The measures employed here and for the payment tariffs do not fully capture long-term measures of social integration and functioning. Employment has been cited as a key factor in recovery oriented systems [16] but did not contribute to payment tariffs.

Recovery is a complex and long term process that may not be achieved within the relatively short period of time of the P4P scheme. Although the study observed outcomes up to two years, only those service users treated in the first year of the P4P schemes were eligible for inclusion in the analysis of outcomes that required a twelve month follow-up.

Interpretation

This article is protected by copyright. All rights reserved. 
In this study, we find that there is no clear link between introduction of a P4P scheme and improvements in treatment outcomes. This finding is consistent with evidence from the P4P evidence base, which has generally only shown improvements in indicators of processes to be (weakly) linked to the introduction of P4P $[2,3,22]$.

Many outcomes such as non-re-presentation for treatment are likely determined by many factors beyond the control of providers. This raises questions as to the suitability of linking harder outcomes to incentive payments, and the potential rewarding/penalisation of providers based on variation in exogenous factors. Whilst the specific tariffs assigned to different indicators and domains varied locally, successful completion and non-re-presentation to treatment comprised the highest share of P4P income for providers (18).

Our findings are consistent with the existing literature, which gives little support to linking payment to outcomes or evidence that introducing P4P can improve outcomes. However, a recent systematic review suggests there is some evidence that P4P can be used to improve performance on specific processes [22]. This is consistent with the findings in this study which showed differentially improved performance on 'within-treatment' indicators such as injecting cessation and abstinence.

Prior to the introduction of the P4P scheme there was concern regarding the potential for 'gaming' whereby treatment services in participating areas might favour selection of clients more likely to achieve the prescribed outcomes. However, the reverse appears to be the case: there was a relative increase in client complexity in participating areas. The reduced initiation of treatment, following initial assessment, observed in participating areas, was due to the delivery pattern within one specific site. The effect was not observed in a post hoc analysis with that site excluded.

Where treatment was received, waiting times were also adversely affected within participating areas. This is likely to be due to the introduction of the assessment and referral system (LASARS). The rationale for these is clear in terms of providing transparency to the alignment of patients with treatment services and payment tariffs. However, they impose an additional layer of administration in the client's access to treatment and appear to have extended the time taken to reach treatment. The P4P scheme was designed to encourage the treatment system to achieve recovery-focussed outcomes. The outcome that most closely aligned to recovery and which, where known, carried the 
highest payment tariff was successful completion of treatment with no subsequent re-presentation. However, this measure has been part of the national set of performance measures published by Public Health England (www.NDTMS.net) for all local areas since 2012 and may therefore have been a priority, to varying degrees, for all areas, regardless of their P4P status. Participating areas performed significantly worse than non-participating areas for this measure, recording a significant and substantive decrease. This suggests a failure of the P4P systems to encourage improvements in primary patient recovery outcomes. The fact that participating areas performed worse in client completions but better in re-presentations among completers opens up the possibility that services were resistant to recording a successful treatment completion until such time as relapse seemed less likely. This may relate to the relatively high payment tariffs associated with re-presentation.

It is plausible that any effect of P4P has been moderated by a greater focus by all treatment services on developing recovery oriented outputs. This shift in emphasis may have confounded the specific effects of P4P. However, participating areas performed worse in a number of these recoveryspecific outcome domains, despite their apparently greater emphasis.

It is possible that the payment tariffs may have conflicted with each other. Despite an emphasis on clients leaving treatment and not re-presenting, many of the client improvements on which tariffs were based may have been perceived as being easier to achieve, or at least more straightforward to measure, among clients who remained in treatment. This may be the case for the in-treatment measures of illicit drug use and injecting, for which participating areas showed better performance. Nevertheless, scheme sites were specifically tasked with improving rates of treatment completion, but their performance on this measure was worse than for non-participating areas. Where effects were identified, these generally reflected a substantive change in participating areas compared to marginal or no change in non-participating areas.

Despite concerns that the first year of the scheme may have reflected a state of organisational flux rather than the actual impact of the schemes, analysis of data from the second year of the scheme, where available, generally mirrored those from the first. Comparison with sites that volunteered but were not selected also largely confirmed that most findings were related to the P4P scheme itself rather than an organisational interest in the model. In addition, narrow confidence intervals in the models confirmed that the data had sufficient power to detect the measured effects. 
Implications for policy and further research

This study has added much needed evidence to the role of P4P schemes in affecting patient outcomes, over and above service performance measures. It adds to the limited evidence base on the effects of P4P schemes that link payments directly to outcomes rather than indicators of processes. In relation to the outcomes associated with recovery from drug misuse, it does not directly support the implementation of these schemes as policy. However, a considerable proportion of commissioning bodies in England are known to have either adopted or to have plans to adopt, a P4P system, so these results have wide and significant implications for this treatment sector.

This article is protected by copyright. All rights reserved. 


\section{References}

1. Van Herck, P., De Smedt, D., Annemans, L., Remmen, R., Rosenthal, M. B. \& Sermeus, W. 2010. Systematic review: Effects, design choices, and context of pay-for-performance in health care. Bmc Health Services Research, 10.

2. Commons M., McGuire T. G., Riordan M. H. 1997. Performance contracting for substance abuse treatment. Health Serv Res 1997; 32: 631.

3. Shen Y., Ellis R. 2002. How profitable is risk selection? A comparison of four risk-adjustment models. Health Econ; 11: 165-174.

4. McLellan A. T., Kemp J., Brooks A., Carise D. 2008. Improving public addiction treatment through performance contracting: the Delaware experiment. Health Policy ; 87: 296-308.

5. Flodgren, G., Eccles, M. P., Shepperd, S., Scott, A., Parmelli, E. \& Beyer, F. R. 2011. An overview of reviews evaluating the effectiveness of financial incentives in changing healthcare professional behaviours and patient outcomes. Cochrane Database of Systematic Reviews.

6. Battye, F. 2015. Payment by Results in the UK: Progress to date and future directions for evaluation. Evaluation, 21, 189-203.

7. Beaulieu, N. D. \& Horrigan, D. R. 2005. Putting smart money to work for quality improvement. Health Services Research, 40, 1318-1334.

8. Casalino, L., Gillies, R. R., Shortell, S. M., Schmittdiel, J. A., Bodenheimer, T., Robinson, J. C., Rundall, T., Oswald, N., Schauffler, H. \& Wang, M. C. 2003. External incentives, information technology, and organized processes to improve health care quality for patients with chronic diseases. Jama-Journal of the American Medical Association, 289, 434-441.

9. Saunders, M., Schattner, P. \& Mathews, M. 2008. Diabetes 'cycles of care' in general practice - Do government incentives help? Australian Family Physician, 37, 781-784.

10. Scott, A., Schurer, S., Jensen, P. H. \& Sivey, P. 2009. The Effects of An Incentive Program on Quality of Care in Diabetes Management. Health Economics, 18, 1091-1108.

11. De Bruin, S. R., Baan, C. A. \& Struijs, J. N. 2011. Pay-for-performance in disease management: a systematic review of the literature. Bmc Health Services Research, 11.

12. Farrar, S., YI, D., Sutton, M., Chalkley, M., Sussex, J. \& Scott, A. 2009. Has payment by results affected the way that English hospitals provide care? Difference-in-differences analysis. British Medical Journal, 339.

13. Audit Commission. 2012. Briefing: Payment by Results for Locval Services.

14. O'Connor, R. J. \& Neumann, V. C. 2006. Payment by results or payment by outcome? The history of measuring medicine. Journal of the Royal Society of Medicine, 99, 226-231.

15. Maynard, A., Street, A. \& Hunter, R. 2011. Using 'payment by results' to fund the treatment of dependent drug users-proceed with care! Addiction, 106, 1725-1729.

16. Home Office. (2010). Drug Strategy 2010 Reducing Demand, Restricting Supply, Building Recovery: Supporting People to Live a Drug Free Life. London: Home Office.

17. Mayor, S. 2011. Payment by results may undermine services for drug users, warn specialists. British Medical Journal, 342.

18. Mason, T., Sutton, M., Whittaker, W., M'sweeney, T., Millar, T., Donmall, M., Jones, A. \& Pierce, M. 2015. The impact of paying treatment providers for outcomes: difference-in- 
differences analysis of the "payment by results for drugs recovery' pilot. Addiction, 110, 1120-1128.

19. Marsden, J., Farrell, M., Bradbury, C., Dale-Perera, A., Eastwood, B., Roxburgh, M. \& Taylor, S. 2008. Development of the treatment outcomes profile. Addiction, 103, 1450-1460.

20. Pierce, M., Bird, S. M., Hickman, M. \& Millar, T. 2015. National record linkage study of mortality for a large cohort of opioid users ascertained by drug treatment or criminal justice sources in England, 2005-2009 (vol 146, pg 17, 2015). Drug and Alcohol Dependence, 156, 315-315.

21. Pierce, M., Bird, S. M., Hickman, M., Marsden, J., Dunn, G., Jones, A. \& Millar, T. 2016. Impact of treatment for opioid dependence on fatal drug-related poisoning: a national cohort study in England. Addiction, 111, 298-308.

22. Mendelson, A., Kondo, K., Damberg, C., Low, A., Motúapuaka, M., Freeman, M., O'neil, M., Relevo, R. and Kansagara, D., 2017. The Effects of Pay-for-Performance Programs on Health, Health Care Use, and Processes of Care. A Systematic Review. Annals of internal medicine, 166(5), pp.341-353.

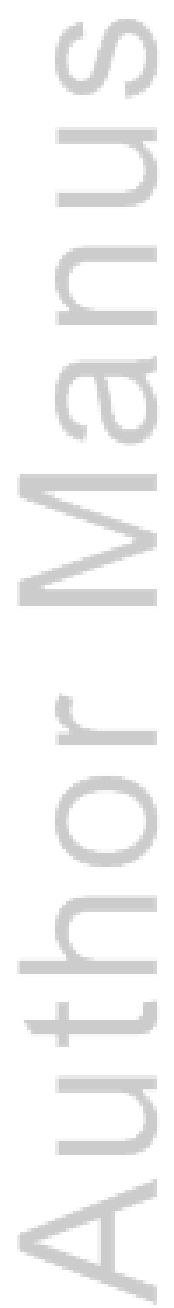

This article is protected by copyright. All rights reserved. 
Table 1 Client characteristics before and during the P4P scheme: includes covariates used in standard models

\begin{tabular}{|c|c|c|c|c|c|c|c|}
\hline & \multicolumn{2}{|c|}{$\begin{array}{r}\text { Participating } \\
\text { areas }\end{array}$} & \multicolumn{2}{|c|}{$\begin{array}{r}\text { Non-participating } \\
\text { areas }\end{array}$} & \multicolumn{3}{|c|}{$\begin{array}{r}\text { Adjusted difference in } \\
\text { differences }\end{array}$} \\
\hline & $\begin{array}{r}\text { Before } \\
\text { scheme } \\
\%\end{array}$ & $\begin{array}{r}\text { During } \\
\text { scheme } \\
\%\end{array}$ & $\begin{array}{r}\text { Before } \\
\text { scheme } \\
\%\end{array}$ & $\begin{array}{r}\text { During } \\
\text { scheme } \\
\%\end{array}$ & $\begin{array}{l}\text { Odds } \\
\text { Ratio }\end{array}$ & $95 \% \mathrm{Cl}$ & $\begin{array}{r}P \\
\text { value }\end{array}$ \\
\hline Opiate user & 61.6 & 64.1 & 66.3 & 62.5 & 1.30 & $1.22,1.38$ & $<0.001$ \\
\hline Crack user & 23.9 & 26.3 & 31.4 & 29.6 & 1.16 & $1.09,1.25$ & $<0.001$ \\
\hline Benzodiazepine user & 6.2 & 4.9 & 8.2 & 7.3 & 0.33 & $0.03,3.03$ & 0.330 \\
\hline Cannabis user & 35.7 & 30.8 & 29.8 & 32.1 & 0.72 & $0.68,0.77$ & $<0.001$ \\
\hline CJS referred & 26.7 & 23.5 & 32.4 & 31.0 & 1.08 & $0.99,1.16$ & 0.054 \\
\hline Previously treated & 55.8 & 57.1 & 59.4 & 60.0 & 1.02 & $0.96,1.08$ & 0.599 \\
\hline Accommodation issues & 22.9 & 24.5 & 24.3 & 24.6 & 1.07 & $0.97,1.11$ & 0.284 \\
\hline Current injector & 20.5 & 20.7 & 16.8 & 16.4 & 1.10 & $1.02,1.19$ & 0.010 \\
\hline Pregnant & 1.0 & 1.0 & 1.2 & 1.1 & 1.04 & $0.80,1.37$ & 0.747 \\
\hline Receiving mental health services & 14.6 & 20.0 & 14.8 & 17.1 & 1.17 & $1.09,1.27$ & $<0.001$ \\
\hline Unemployed & 81.2 & 77.8 & 82.0 & 81.2 & 1.04 & $0.97,1.11$ & 0.221 \\
\hline Gender (Female) & 24.0 & 22.9 & 23.8 & 23.1 & 0.97 & $0.91,1.05$ & 0.474 \\
\hline Mean age & 32.5 & 33.3 & 33.5 & 34.3 & $0.16^{\dagger}$ & - & 0.231 \\
\hline $\pm S D$ & \pm 8.7 & \pm 8.9 & \pm 8.8 & \pm 9.1 & & $0.10,0.42$ & \\
\hline Total treatment journeys & 10,716 & 10,012 & 143,459 & 138,929 & & & \\
\hline
\end{tabular}

Unless otherwise indicated, difference in difference estimates are interpreted as changes on the odds-ratio scale

${ }^{\dagger}$ Parameter interpreted as a difference in difference change in means 
Table 2: Difference in difference estimates of impact on outcomes

\begin{tabular}{|c|c|c|c|c|c|c|c|c|}
\hline \multirow[t]{2}{*}{ Outcome } & \multicolumn{2}{|c|}{ Participating areas } & \multicolumn{2}{|c|}{$\begin{array}{c}\text { Non-participating } \\
\text { areas }\end{array}$} & \multicolumn{3}{|c|}{ Adjusted difference in differences } & \multirow[t]{2}{*}{$\mathrm{n}$} \\
\hline & $\begin{array}{r}\text { Before } \\
\text { scheme }\end{array}$ & During scheme & $\begin{array}{r}\text { Before } \\
\text { scheme }\end{array}$ & $\begin{array}{r}\text { During } \\
\text { scheme }\end{array}$ & Odds-Ratio & $95 \% \mathrm{Cl}$ & $p$ value & \\
\hline \multicolumn{9}{|l|}{ Treatment access } \\
\hline Initiation of treatment intervention (\%) & 98.06 & 91.98 & 98.03 & 98.569 & 0.17 & $\begin{array}{l}0.14, \\
0.21,\end{array}$ & $<0.001$ & 303,116 \\
\hline Waiting time under three weeks (\%) & 95.75 & 92.84 & 94.73 & 94.87 & 0.36 & $0.31,0.42$ & $<0.001$ & 297,287 \\
\hline \multicolumn{9}{|l|}{ Treatment exit } \\
\hline Successful completion of treatment (within 12 months) (\%) & 33.99 & 24.47 & 27.49 & 28.93 & 0.60 & $0.53,0.67$ & $<0.001$ & 154,054 \\
\hline Completion (6 months) \& non-representation (12 months) (\%) & 19.65 & 14.01 & 15.68 & 17.45 & 0.63 & $0.52,0.77$ & 0.001 & 79,543 \\
\hline Unplanned discharge (12 months) (\%) & 38.85 & 46.56 & 41.27 & 40.90 & 1.25 & $1.14,1.38$ & 0.004 & 154,054 \\
\hline Non-representation (12 months), if treatment completed (\%) & 81.93 & 89.95 & 85.08 & 85.93 & 2.33 & $1.33,4.08$ & 0.003 & 15,380 \\
\hline \multicolumn{9}{|l|}{ Outcomes at latest assessment within treatment } \\
\hline Abstinence from illicit drugs (\%) & 21.90 & 27.35 & 22.62 & 22.02 & 1.50 & $1.30,1.72$ & $<0.001$ & 96,119 \\
\hline Not injecting at follow-up (\%) & 84.89 & 84.23 & 87.16 & 85.62 & 1.32 & $1.10,1.59$ & $<0.001$ & 96,869 \\
\hline Resolution of housing problem at follow-up (\%) & 31.43 & 34.97 & 34.65 & 35.54 & 1.30 & $0.93,1.79$ & 0.120 & 16,650 \\
\hline \multicolumn{9}{|l|}{ Social outcomes, 1 year follow-up } \\
\hline Drug related poisoning mortality ( $\mathrm{n}$ per 1,000 person years) & 1.71 & 1.41 & 1.35 & 1.50 & $0.62^{+}$ & $0.28,1.36$ & 0.240 & 147,457 \\
\hline Recorded acquisitive crime (rate per person year) & 0.67 & 0.89 & 0.73 & 0.84 & $0.93^{\ddagger}$ & $0.84,1.03$ & 0.173 & 348,619 \\
\hline
\end{tabular}

Unless otherwise indicated, difference in difference estimates are interpreted as changes on the odds-ratio scale, adjusting for: age; gender; opioid /crack /benzodiazepine /cocaine /amphetamine /or cannabis use; whether previously treated; presence of co-occurring mental illness; whether pregnant; employment status; injecting status; source of treatment referral; years since first drug use; parenting status; and accommodation status.

This article is protected by copyright. All rights reserved. 
${ }^{\dagger}$ Parameter interpreted as a difference in difference change in Hazard Ratio

${ }^{\ddagger}$ Parameter interpreted as a difference in difference change in rate

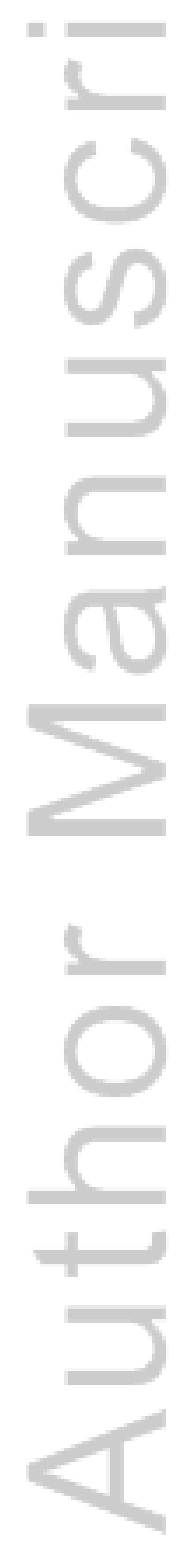

This article is protected by copyright. All rights reserved. 
Table 3 Difference in difference estimates of impact on outcomes - sensitivity analyses

\begin{tabular}{|c|c|c|c|}
\hline \multirow[t]{2}{*}{ Outcome } & \multicolumn{3}{|c|}{ Adjusted difference in differences } \\
\hline & $\begin{array}{r}\text { Odds/Hazard- } \\
\text { Ratio }\end{array}$ & $95 \% \mathrm{Cl}$ & $p$ value \\
\hline \multicolumn{4}{|l|}{ Successful completion of treatment } \\
\hline Client level P4P status & 0.57 & $0.49,0.65$ & $<0.001$ \\
\hline $13 / 14$ cohort only & 0.60 & $0.53,0.67$ & $<0.001$ \\
\hline Volunteer, non-selected areas as control & 0.60 & $0.53,0.69$ & $<0.001$ \\
\hline \multicolumn{4}{|c|}{ Completion (6 months) \& non-representation (12 months) } \\
\hline Client level P4P status & 0.46 & $0.36,0.58$ & $<0.001$ \\
\hline $13 / 14$ cohort only & $*$ & * & * \\
\hline Volunteer, non-selected areas as control & 0.65 & $0.52,0.81$ & $<0.001$ \\
\hline \multicolumn{4}{|l|}{ Re-presentation (12 months), if completed } \\
\hline Client level P4P status & 0.43 & $0.23,0.82$ & 0.010 \\
\hline $13 / 14$ cohort only & * & $*$ & * \\
\hline Volunteer, non-selected areas as control & 0.29 & $0.15,0.56$ & $<0.001$ \\
\hline \multicolumn{4}{|l|}{ Abstinence from illicit drugs } \\
\hline Client level P4P status & 1.71 & $1.46,2.00$ & $<0.001$ \\
\hline $13 / 14$ cohort only & 1.40 & $1.20,1.64$ & $<0.001$ \\
\hline Volunteer, non-selected areas as control & 1.60 & $\begin{array}{r}1.36,1 \\
.88\end{array}$ & $<0.001$ \\
\hline \multicolumn{4}{|l|}{ Injecting at follow-up } \\
\hline Client level P4P status & 0.71 & $0.57,0.88$ & 0.002 \\
\hline $13 / 14$ cohort only & 0.83 & $0.68,01.01$ & 0.068 \\
\hline Volunteer, non-selected areas as control & 0.63 & $0.51,0.78$ & $<0.001$ \\
\hline
\end{tabular}

* Not available within study timeframe, due to length of follow-up period 


\section{University Library}

\section{- M M I N E R VA A gateway to Melbourne's research publications}

Minerva Access is the Institutional Repository of The University of Melbourne

\section{Author/s:}

Jones, A;Pierce, M;Sutton, M;Mason, T;Millar, T

Title:

Does paying service providers by results improve recovery outcomes for drug misusers in treatment in England?

\section{Date:}

2018-02-01

\section{Citation:}

Jones, A., Pierce, M., Sutton, M., Mason, T. \& Millar, T. (2018). Does paying service providers by results improve recovery outcomes for drug misusers in treatment in England? ADDICTION, 113 (2), pp.279-286. https://doi.org/10.1111/add.13960.

Persistent Link:

http://hdl.handle.net/11343/293365 